\title{
BMJ
}

\section{Prevalence and structural correlates of gender based violence among a prospective cohort of female sex workers}

\author{
Kate Shannon, assistant professor, ${ }^{1,2}$ T Kerr, assistant professor, ${ }^{1,2} \mathrm{~S}$ A Strathdee, professor and chair, ${ }^{3}$ ) \\ Shoveller, professor, ${ }^{2}$ J S Montaner, professor and director, ${ }^{1,2} \mathrm{M}$ W Tyndall, associate professor ${ }^{1,2}$
}

\begin{abstract}
British Columbia Centre for Excellence in HIV/AIDS St Paul's Hospital, Vancouver, BC V6Z 1Y6, Canada

${ }^{2}$ Faculty of Medicine, University of British Columbia Vancouver, BC V6T 1Z3, Canada

${ }^{3}$ Division of Global Public Health, University of California San Diego School of Medicine, La Jolla, CA 92093-0507, USA

Correspondence to: K Shannon

kshannon@cfenet.ubc.ca

Cite this as: BMJ 2009;339:b2939 doi:10.1136/bmj.b2939
\end{abstract}

\section{ABSTRACT}

Objective To examine the prevalence and structural correlates of gender based violence against female sex workers in an environment of criminalised prostitution. Design Prospective observational study.

Setting Vancouver, Canada during 2006-8.

Participants Female sex workers 14 years of age or older (inclusive of transgender women) who used illicit drugs (excluding marijuana) and engaged in street level sex work.

Main outcome measure Self reported gender based violence.

Results Of 267 female sex workers invited to participate, 251 women returned to the study office and consented to participate (response rate of $94 \%$ ). Analyses were based on 237 female sex workers who completed a baseline visit and at least one follow-up visit. Of these 237 female sex workers, $57 \%$ experienced gender based violence over an 18 month follow-up period. In multivariate models adjusted for individual and interpersonal risk practices, the following structural factors were independently correlated with violence against female sex workers: homelessness (adjusted odds ratio for physical violence (aOR physicalviolence $) 2.14,95 \%$ confidence interval 1.34 to 3.43; adjusted odds ratio for rape $\left(\mathrm{aOR}_{\text {rape }}\right) 1.73,1.09$ to 3.12); inability to access drug treatment (adjusted odds ratio for client violence $\left(\mathrm{aOR}_{\text {clientviolence }}\right) 2.13,1.26$ to 3.62; aOR physicalviolence $1.96,1.03$ to 3.43 ); servicing clients in cars or public spaces $\left(\mathrm{aOR}_{\text {clientviolence }} 1.50,1.08\right.$ to 2.57 ); prior assault by police $\left(\mathrm{aOR}_{\text {clientviolence }} 3.45,1.98\right.$ to 6.02 ; aOR rape $2.61,1.32$ to 5.16 ); confiscation of drug use paraphernalia by police without arrest ( $\mathrm{aOR}_{\text {physicalviolence }} 1.50,1.02$ to 2.41 ); and moving working areas away from main streets owing to policing (aOR clientviolence $2.13,1.26$ to 3.62).

Conclusions Our results demonstrate an alarming prevalence of gender based violence against female sex workers. The structural factors of criminalisation, homelessness, and poor availability of drug treatment independently correlated with gender based violence against street based female sex workers. Socio-legal policy reforms, improved access to housing and drug treatment, and scale up of violence prevention efforts, including police-sex worker partnerships, will be crucial to stemming violence against female sex workers.

\section{INTRODUCTION}

Rights violations and abuses experienced by female sex workers are seldom considered in discussions of violence against women, as shown by a review of the global scope and magnitude of gender based violence. ${ }^{1}$ The United Nations Convention on the Elimination of All Forms of Discrimination against Women defined the term "gender based abuse" as "any act of gender based violence that results in, or is likely to result in, physical, sexual or psychological harm or suffering to women, including threats of such acts, coercion, or arbitrary deprivation of liberty, whether occurring in public or in private life." ${ }^{2}$ This definition encompasses rape, torture, mutilation, sexual slavery, forced impregnation, and murder, and distinguishes male perpetrated violence against women from other non-gender based forms of violence. Gender based violence has been recognised as a global public health and human rights problem that leads to high rates of morbidity and mortality, including gynaecological problems, sexually transmitted infections, depression, post-traumatic stress disorder, substance dependence, suicide, and mortality. ${ }^{3-5}$

Despite extensive evidence documenting the severe adverse health outcomes associated with gender based violence, our understanding of the magnitude of violence against women has been largely drawn from data on partner violence. ${ }^{145}$ Additionally, although individual and interpersonal correlates of gender based violence have been well described, there are no empirical models that account for larger structural inequities that could promote gender based violence.

Of particular concern is the fact that gender based violence and gender inequity have increasingly been cited as important determinants of a woman's risk of HIV infection. ${ }^{467}$ Among drug involved and sex work populations, violence has been associated with an elevated likelihood of acquiring sexually transmitted infections or HIV through unprotected sex, the exchange of sex for drugs or money, multiple concurrent sex partnerships, and sex with a risky partner (for example, a partner positive for antibodies to HIV or a partner who has multiple sex partners) ${ }^{89}$ Furthermore, the synergistic relationship between crack cocaine smoking and survival sex among female sex workers 
has been shown to exacerbate violence and exploitation against women and increase the risk of acquiring sexually transmitted infections or HIV, resulting in reduced control of female sex workers over the negotiation of HIV risk reduction practices with clients. ${ }^{10}$

In 2002, the Joint United Nations Programme on HIV/AIDS (UNAIDS) called for the decriminalisation of sex work, recognising the longstanding promotion by public health advocates and sex workers of safer working conditions and protection from violence. $^{11}$ Although UNAIDS retreated from this endorsement in 2007, ${ }^{12}$ the UN secretary general, Ban Ki-moon, reconfirmed the organisation's position against punitive sanctions targeting sex workers at the UN High-level Meeting on HIV/AIDS in June 2008. Despite these policy statements, many countries, including Canada and the UK, continue to promote conflicting sex work regulations that maintain the buying and selling of sexual services as legal but criminalise soliciting for sexual services in public spaces, living off the benefits of prostitution, and working indoors in managed or cooperative settings (for example, brothels) ${ }^{13-16}$ Enforcement of these criminal sanctions has been shown to create "tolerance zones" in outlying and isolated public spaces that are then subject to police crackdowns and unwritten rules of engagement between police, clients, and sex workers. Importantly, a growing body of qualitative evidence has documented the adverse impact of street policing strategies on the health and safety of female sex workers ${ }^{17-21}$; and yet, there has been no empirical investigation to date evaluating the relationship of criminalisation and enforcement based policing strategies with the likelihood of violence against female sex workers.

In Canada over the past two decades, urban centres have experienced epidemics of violence against street based female sex workers that have been posited to coincide with prohibitive policy changes and enforcement based strategies, such as police crackdowns. ${ }^{13-15}$ A study in Vancouver, British Columbia, of women who used injection drugs between 1996 and 2002, the majority of whom were in street based work, showed a 47 -fold higher likelihood of mortality in this group compared with an age matched sample of the general population, with homicide being the most common cause of death. ${ }^{22}$ Widespread scrutiny over the delayed response by police and the judicial system to the deaths of female sex workers led to an extensive police investigation of over 69 women missing from the streets of Vancouver and the inception of the Missing Women's Task Force in 1999, which was estimated to have cost more than $\$$ C116 million ( $£ 65$ million; $€ 75$ million; $\$ 107$ million) by the end of $2007 .{ }^{23}$

This study aims to identify the prevalence and structural correlates of violence against female sex workers by using longitudinal data derived from a prospective cohort of street based female sex workers in Vancouver, Canada. Given that sexual and physical violence have been shown to be conceptually different, ${ }^{6}$ we further hypothesised that client perpetrated violence would be conceptually unique owing to the specific context of a sexual transaction; therefore, three separate violence experiences - physical, sexual, and client perpetrated—were modelled separately.

\section{METHODS}

The Maka Project is a community based HIV prevention research partnership that has been described in detail elsewhere. ${ }^{24}$ Briefly, between 2006 and 2008, street based female sex workers were enrolled in an open prospective cohort and participated in baseline and six monthly follow-up visits that included an interview questionnaire and voluntary screening for HIV. On the basis of previous research that identified 100\% substance use among street based female sex workers in Vancouver, ${ }^{25}$ eligibility criteria were defined as being a woman aged 14 years or older who used illicit drugs (excluding marijuana) and engaged in street level sex work. Determining a representative sample of female sex workers is difficult owing to the unknown size and boundaries of this population; therefore, we mapped areas with over 60 female sex workers and identified solicitation spaces for targeted outreach and recruitment. Time space sampling was used to systematically sample all women (inclusive of transgender women) at staggered times and locations in these solicitation areas. ${ }^{26}$

At baseline and follow-up visits, trained peer researchers (that is, former and current female sex workers) administered a detailed semistructured questionnaire with questions related to demographics, health service use, working conditions, violence, and sexual and drug risk practices. In addition, voluntary HIV screening using the new point of care rapid INSTI test (bioLytical Laboratories, Richmond, BC, Canada; specificity $99.3 \%$, sensitivity $99.6 \%$ ) was conducted by the project nurse, supported by pre-test and post-test counselling. Tests positive for HIV antibodies were confirmed by Western blot. Detailed health and violence questions were then asked by the nurse in order to facilitate counselling and referral to support services.

\section{Modelling \\ Dependent variables}

Given that serial measures over three follow-up visits were available, we were able to analyse the data longitudinally. The following three categories of violence experiences perpetrated by men were considered at each six month interval and modelled separately: $(a)$ physical violence ("Have you been physically abused by someone (excluding clients) in the last six months? This may include partner, pimp, dealer, police, security guard, stranger, or other"); (b) rape ("Have you been forced to have sex (penetrative) against your will (excluding clients) in the last six months?"); and (c) client perpetrated violence ("Have you experienced a 'bad date' in the last six months?"). Respondents who answered "yes" to having experienced a "bad date" in the past six months were asked to classify the incident (s) of violence into the following categories: verbal harassment; abduction or kidnap; sexual assault; rape; strangling; physical assault or beating; assault with a weapon; being thrown out of moving car; or other. 


\section{Independent variables}

Specific environmental and structural factors collected at baseline and follow-up visits were considered on the basis of evidence in the literature and relationships hypothesised a priori. These factors were: homelessness; having tried but been unable to access drug treatment; place of servicing client (car or outdoor public space compared with indoor settings (for example, hourly room, sauna)); and current and historical street policing strategies. Current policing variables (reported at baseline and at each six monthly follow-up visit) included confiscation of drug use paraphernalia without arrest and moving working areas away from main streets as a result of policing. Historical police assault was recorded as self reported police assault before first baseline visit (defined as self reported physical assault and/or having been forced to provide sexual favours to police). Although the majority of police officers in Canada are male, the interactions could have involved female police officers.

Individual variables considered as potential confounders owing to their known or hypothesised relationship with gender based violence and one or more independent variable(s) included age (defined as $\leq 24$ years $v>24$ years of age); ethnicity; HIV antibody status; and drug use patterns. Aboriginal ethnicity (for example, First Nation, Méti, Inuit) compared with non-Aboriginal ethnicity was considered owing to evidence of an elevated prevalence of trauma among Aboriginal people. HIV antibody status was based on HIV screening results at each study visit. Similar to previous analyses, ${ }^{25}$ drug use patterns included any cocaine or heroin injection, crystal methamphetamine use (injection or non-injection), or crack cocaine smoking.

Five risky interpersonal practices were also considered as potential confounders owing to their known or hypothesised relationship with gender based violence and one or more independent variable(s): (a) having a male sex partner who injects drugs; $(b)$ exchanging sex while high on injection or non-injection drugs; $(c)$ having unprotected sex; ( $d$ ) being pressured into sex (vaginal or anal) without a condom; and (e) having a male intimate partner who procures drugs for use by the sex worker. Consensual unprotected sex was reported as inconsistent condom use for vaginal, anal, or oral sex with regular clients ("regulars"), one time clients ("johns"), and primary partners. Given the different risks associated with penetrative sex compared with oral sex, only unprotected vaginal and anal sex were considered in our analyses. The micro level practice of relying on a male intimate partner to procure drugs was considered on the basis of our qualitative research documenting female sex workers' experiences of having a primary partner limit their ability to negotiate violence prevention strategies through reducing access to material resources. ${ }^{18}$ All models were adjusted for childhood sexual abuse owing to its known confounding relationship with experiences of violence in adulthood, criminal behaviour, and negotiation of sexual risk reduction.

\section{Statistical analyses}

Analyses were restricted to female sex workers who attended a baseline visit and at least one follow-up visit. The baseline variables considered were demographic variables, childhood sexual abuse, and historical assault by police. All other variables were treated as time updated covariates that referred to experiences occurring during the previous six month period.

We examined bivariate associations and tested for potential collinearity or effect modification of individual, interpersonal, and environmental and structural variables with experiences of each type of violence by using generalised estimating equations and a working correlation matrix. Fisher's test of exact probability was also used to compute $\mathrm{P}$ values when one or more of the observations was less than or equal to five. We used generalised estimating equations for binary outcomes, with logit link for the analyses of correlated data because the factors potentially associated with violence during follow-up were serial (time dependent) measures. In addition, models generated from generalised estimating equations take into account the correlation between repeated measures for each subject. Data from every participant follow-up visit was considered in the analyses. Given the conceptual differences in the types of violence episodes, we then fitted separate multivariate logistic generalised estimating equation models for each of the three violence outcomes (physical violence, rape, and client perpetrated violence), adjusting for known or potential individual and interpersonal confounders and variables that retained significance with violence in bivariate analyses at $\mathrm{P}<0.10$. Variables were considered significant in multivariate analyses if they retained significance at $\mathrm{P}<0.05$. All reported $\mathrm{P}$ values are two sided with $95 \%$ confidence intervals. Given that each violence outcome was modelled separately, unadjusted and adjusted odds ratios of associations between independent variables and outcome measures are reported separately for each specific violence outcome.

\section{RESULTS}

Of 267 female sex workers invited to participate, 251 women returned to the study office and consented to participate (response rate of 94\%). A total of 237 women completed a baseline visit and at least one follow-up visit, with a total of 575 observations available over three visits (median visits 2 , interquartile range (IQR) 2-3). Approximately half (113/237 (48\%)) of the women self identified as Aboriginal and 43\% $(102 / 237)$ as white. The median age at baseline was 36 years (25-41 years) and the median age of sex work initiation was 15 years (13-21 years). Twenty per cent $(47 / 237)$ were young women aged less than 24 years. The prevalence of HIV infection was $23 \%$ (55/237). The majority of women (206/237 (87\%)) reported "absolute homelessness" (living on the street) at least once in their lifetime, with approximately half $(104 / 237(48 \%))$ reporting homelessness over the 18 months of follow-up. One fifth (47/237) reported having tried but been unable to access drug treatment, 
Table 1|Type of client perpetrated violence reported by the $70(30 \%)$ street based female sex workers who experienced client perpetrated violence over 18 months of follow-up

\begin{tabular}{lc}
$\begin{array}{l}\text { Type of client perpetrated } \\
\text { violence }\end{array}$ & $\begin{array}{c}\text { Total number female sex workers } \\
(\mathrm{n}(\%))\end{array}$ \\
Verbal harassment & $70(100)$ \\
\hline Physical assault or beating & $47(67)$ \\
\hline Rape or sexual assault & $34(49)$ \\
\hline Assault with a weapon & $31(44)$ \\
\hline Strangling & $19(27)$ \\
\hline Abduction or kidnap & $18(26)$ \\
\hline Attempted sexual assault & $15(21)$ \\
\hline Thrown out of a moving car & $14(20)$ \\
\hline Other* & $11(16)$ \\
\hline
\end{tabular}

In total, 70/237 (30\%) of the female sex workers reported client perpetrated violence. Median number of incidents: 1 (interquartile range 1-2).

* "Other" responses included being robbed; being held against will or locked in car; and being assaulted under the influence of a date rape drug (for example, flunitrazepam (Rohypnol)).

with long waiting lists being the primary reason for inability to access drug treatment $(45 / 47(96 \%))$. One fifth (48/237) reported one or more dependent children (median 2, IQR 1-3), with 32\% (76/237) reporting having had at least one child apprehended by social welfare services (median 3, IQR 1-4).

A total of $57 \%(136 / 237)$ of women experienced violence at least once over the 18 month follow-up period, with $38 \%$ (90/237) reporting physical violence, $25 \%(60 / 237)$ rape, and $30 \%(70 / 237)$ client perpetrated violence. Table 1 describes the specific incidents of client perpetrated violence reported by female sex workers.

Tables 2, 3, and 4 show the unadjusted and adjusted associations in the multivariate models for each violence outcome (physical violence, rape, and client perpetrated violence). In multivariate models that adjusted for individual and interpersonal risk practices, the environmental and structural factors independently associated with violence against female sex workers were homelessness (adjusted odds ratio for physical violence $\left(\mathrm{aOR}_{\text {physicalviolence }}\right) 2.14,95 \% \mathrm{CI}$ 1.34 to 3.43 ; adjusted odds ratio for rape $\left(\mathrm{aOR}_{\text {rape }}\right)$ $1.73,1.09$ to 3.12 ), inability to access drug treatment ( $\mathrm{aOR}_{\text {physicalviolence }} 1.96,1.03$ to 3.43 ; adjusted odds ratio for client perpetrated violence $\left(\mathrm{aOR}_{\text {clientviolence }}\right)$ $2.13,1.26$ to 3.62$)$, servicing clients in cars or public spaces $\left(\mathrm{aOR}_{\text {clientviolence }} 1.50,1.08\right.$ to 2.57$)$, prior assault by police $\left(\mathrm{aOR}_{\text {rape }} 2.61,1.32\right.$ to 5.16 ; $\mathrm{aOR}_{\text {clientviolence }}$ $3.45,1.98$ to 6.02 ), confiscation of drug use paraphernalia by police without arrest $\left(\mathrm{aOR}_{\text {physicalviolence }}\right.$ $1.50,1.02$ to 2.41), and moving working areas away from main streets owing to policing $\left(\mathrm{aOR}_{\text {clientviolence }}\right.$ $2.13,1.26$ to 3.62$)$.

\section{DISCUSSION}

Our results demonstrate an alarming prevalence of gender based violence among a sample of street based female sex workers. Furthermore, we found that the environmental and structural factors of homelessness, inability to access drug treatment, servicing

Table 2 | Bivariate and multivariate models for individual, interpersonal (partner level), and environmental and structural factors correlated with physical violence against street based female sex workers

Physical violence during 18 months of follow-up Unadjusted odds ratio $(95 \% \mathrm{Cl}) \quad$ Adjusted odds ratio $(95 \% \mathrm{Cl})$

Individual factors

\begin{tabular}{|c|c|c|}
\hline Youth ( $\leq 24$ years of age) & $1.25(0.72$ to 2.19$)$ & - \\
\hline Aboriginal ethnicity & $0.83(0.52$ to 1.33$)$ & - \\
\hline HIV positive status & $0.56(0.31$ to 1.01$)$ & - \\
\hline Cocaine injection & $1.20(0.73$ to 1.95$)$ & - \\
\hline Heroin injection & $1.34(0.85$ to 2.10$)$ & - \\
\hline Crystal methamphetamine use & $1.25(0.73$ to 2.16$)$ & - \\
\hline Crack cocaine smoking & $1.00(0.56$ to 1.82$)$ & - \\
\hline \multicolumn{3}{|l|}{ Interpersonal (partner level) factors } \\
\hline Unprotected sex & 1.24 (0.77 to 1.98$)$ & - \\
\hline Pressured into sex without a condom & $2.40(1.53 \text { to } 3.77)^{\star}$ & $2.23(1.40$ to 3.61$)$ \\
\hline Primary sex partner injects drugs & $1.54(0.86$ to 2.75$)$ & - \\
\hline Primary partner procured drugs for female sex worker & $1.67(0.94$ to 2.71$)$ & - \\
\hline Exchanged sex while high & $1.00(0.66$ to 1.51$)$ & - \\
\hline \multicolumn{3}{|l|}{ Environmental and structural factors } \\
\hline Homeless & $2.13(1.36 \text { to } 3.35)^{\star}$ & $2.14(1.34$ to 3.43$)$ \\
\hline Unable to access drug treatment & $2.43(1.33 \text { to } 4.41)^{\star}$ & $1.96(1.03$ to 3.43$)$ \\
\hline Serviced clients in cars and public spaces & $1.87(1.06 \text { to } 3.02)^{\star}$ & $1.56(0.97$ to 2.75$)$ \\
\hline Prior assault by police & $2.65(0.95 \text { to } 3.87)^{\star}$ & $2.23(0.78$ to 3.65$)$ \\
\hline Police confiscated drug use paraphernalia (without arrest) & $1.96(1.23 \text { to } 3.12)^{\star}$ & $1.50(1.02$ to 2.41$)$ \\
\hline Moved working areas away from main streets owing to local policing & 1.87 (0.89 to 3.05$)$ & - \\
\hline
\end{tabular}


Table 3|Bivariate and multivariate models for individual, interpersonal (partner level), and environmental and structural factors correlated with rape experienced by street based female sex workers

\begin{tabular}{|c|c|c|}
\hline & \multicolumn{2}{|c|}{ Rape during 18 months of follow-up } \\
\hline & Unadjusted odds ratio $(95 \% \mathrm{Cl})$ & Adjusted odds ratio $(95 \% \mathrm{Cl})$ \\
\hline \multicolumn{3}{|l|}{ Individual factors } \\
\hline Youth ( $\leq 24$ years of age) & $1.81(0.98 \text { to } 3.36)^{*}$ & 1.67 (0.82 to 2.97$)$ \\
\hline Aboriginal ethnicity & 1.07 (0.61 to 1.89$)$ & - \\
\hline HIV positive status & $0.53(0.26$ to 1.11$)$ & - \\
\hline Cocaine injection & $0.98(0.56$ to 1.74$)$ & - \\
\hline Heroin injection & 1.47 (0.86 to 2.54$)$ & - \\
\hline Crystal methamphetamine use & $1.23(0.71$ to 2.16$)$ & - \\
\hline Crack cocaine smoking & 1.42 (0.69 to 2.92$)$ & - \\
\hline \multicolumn{3}{|l|}{ Interpersonal (partner level) factors } \\
\hline Unprotected sex & $2.13(1.30 \text { to } 3.42)^{*}$ & $1.82(1.01$ to 3.25$)$ \\
\hline Pressured into sex without a condom $†$ & $1.82(1.06$ to 3.13$)$ & - \\
\hline Primary sex partner injects drugs $†$ & 1.75 (1.02 to 2.97$)$ & - \\
\hline Primary partner procured drugs for female sex worker & $2.00(1.09 \text { to } 3.67)^{*}$ & 1.63 (1.03 to 2.82$)$ \\
\hline Exchanged sex while high & $0.80(0.51$ to 1.26$)$ & - \\
\hline \multicolumn{3}{|l|}{ Environmental and structural factors } \\
\hline Homeless & $1.81(1.10 \text { to } 3.36)^{\star}$ & 1.73 (1.09 to 3.12$)$ \\
\hline Unable to access drug treatment & $1.66(0.95$ to 2.90$)$ & - \\
\hline Serviced clients in cars and public spaces & $1.38(0.78$ to 2.46$)$ & - \\
\hline Prior assault by police & $3.12(1.61 \text { to } 6.04)^{\star}$ & $2.61(1.32$ to 5.16$)$ \\
\hline Police confiscated drug use paraphernalia (without arrest) & $1.21(0.73$ to 2.00$)$ & - \\
\hline Moved working areas away from main streets owing to local policing & $1.42(0.89$ to 2.27$)$ & - \\
\hline
\end{tabular}

clients in cars or public spaces, and enforcement based policing strategies were independently associated with gender based violence, even after adjustment for the potential confounding effects of individual and interpersonal risk practices. Although previous research samples suggest that the lifetime prevalence of violence among female sex workers is between $50 \%$ and $100 \%,{ }^{2728}$ many such estimates have been based solely on reports of client violence. ${ }^{2930}$ In comparison, over half of the women in this sample experienced physical and/or sexual violence over an 18 month period.

\section{Comparison with other studies}

The persistent relationship between enforcement, both of policies on prostitution and those on drug use (for example, confiscation of drug use paraphernalia without arrest and enforced displacement of sex workers to outlying areas), and violence against female sex workers points to the role of criminalisation in enhancing the likelihood of violence against street based female sex workers. Of particular concern, prior assault by police had the strongest correlation with both sexual and client perpetrated violence against female sex workers. In 2000, the World Health Organization classified police officers' excessive use of force as a form of violence, ${ }^{31}$ and yet there is scant empirical evidence with which to characterise the public health impact of police violence. ${ }^{3032}$ Police contact with street involved populations can be pervasive, and evidence suggests that excessive use of force, including violence, can be a characteristic of "police crackdowns" that target street populations. ${ }^{3233}$

A growing body of qualitative evidence documents the multitude of negative outcomes of street policing strategies for female sex workers, including displacement of street based sex markets, disruption of peer networks and informal safety structures, and increased risk of violence and sexually transmitted infections. ${ }^{17-21}$ Police violence against female sex workers has been reported to include excessive use of physical force, forced removal and subsequent abandonment in outlying areas, and coerced sex provided to police in exchange for freedom from detainment, fine, or arrest. $^{16-2132}$ Qualitative evidence suggests that prior police perpetrated assault could increase fear of violence among female sex workers and reduce the likelihood that female sex workers will access police and judicial support as a means of averting future violence by partners, clients, or other third parties. ${ }^{20}$ Epidemiological analyses among street based injecting drug users have consistently linked enforcement strategies with adverse health outcomes, including an elevated likelihood of practices that increase the risk of HIV infection, such as syringe borrowing. ${ }^{34-36}$ Taken together with recent findings from our study mapping geographical "hot spots" in which female sex workers working in outlying and industrial areas are pressured into unprotected sex by clients, ${ }^{37}$ this study demonstrates the potential unintended adverse consequences of enforcement based approaches to sex work. The findings provide new evidence to support global calls 
Table 4|Bivariate and multivariate models for individual, interpersonal (partner level), and environmental and structural factors correlated with client perpetrated violence against street based female sex workers

Client perpetrated violence during 18 months of follow-up

Unadjusted odds ratio $(95 \% \mathrm{Cl}) \quad$ Adjusted odds ratio $(95 \% \mathrm{Cl})$

Individual factors

\begin{tabular}{|c|c|c|}
\hline Youth ( $\leq 24$ years of age) & $1.42(0.78$ to 2.58$)$ & - \\
\hline Aboriginal ethnicity & $0.69(0.41$ to 1.51$)$ & - \\
\hline HIV positive status & $0.52(0.27$ to 1.00$)$ & - \\
\hline Cocaine injection & 0.89 (0.53 to 1.52$)$ & - \\
\hline Heroin injection & 1.04 (0.63 to 1.73$)$ & - \\
\hline Crystal methamphetamine use & $0.69(0.33$ to 1.45$)$ & - \\
\hline Crack cocaine smoking & $1.12(0.57$ to 2.24$)$ & - \\
\hline \multicolumn{3}{|l|}{ Interpersonal (partner level) factors } \\
\hline Unprotected sex & $1.40(0.83$ to 2.37$)$ & - \\
\hline Unprotected sex with a client† & $1.98(1.15$ to 3.42$)$ & - \\
\hline Pressured into sex without a condom & $2.31(1.45 \text { to } 3.69)^{\star}$ & $1.85(1.10$ to 3.10$)$ \\
\hline Primary sex partner injects drugs & $1.18(0.62$ to 2.23$)$ & - \\
\hline Primary partner procured drugs for female sex worker & $1.23(0.71$ to 1.92$)$ & - \\
\hline Exchanged sex while high & $1.10(0.69$ to 1.76$)$ & - \\
\hline \multicolumn{3}{|l|}{ Environmental and structural factors } \\
\hline Homeless & $1.63(0.86$ to 2.67$)$ & - \\
\hline Unable to access drug treatment & $2.50(1.46 \text { to } 4.28)^{\star}$ & $2.13(1.26$ to 3.62$)$ \\
\hline Serviced clients in cars and public spaces & $1.87(1.16 \text { to } 3.02)^{\star}$ & 1.50 (1.08 to 2.57$)$ \\
\hline Prior assault by police & $4.16(2.35 \text { to } 7.36)^{\star}$ & $3.45(1.98$ to 6.02$)$ \\
\hline Police confiscated drug use paraphernalia (without arrest) & $1.34(0.89$ to 2.17$)$ & - \\
\hline Moved working areas away from main streets owing to policing & $2.15(1.36 \text { to } 3.40)^{\star}$ & 2.13 (1.26 to 3.62$)$ \\
\hline
\end{tabular}

for the removal of criminal sanctions targeting sex workers, including statements by UNAIDS, and further support the need for systematic evaluations of the effects of legal strategies on health outcomes among female sex workers and clients.

Of major concern, and to our knowledge not previously documented, is the fact that an inability to access drug treatment was associated with a twofold increase in the odds of both physical and client perpetrated violence. A review of Canada's drug strategy showed that of the \$C368 million targeted at illicit drug use, $73 \%$ were spent on enforcement based initiatives and only $14 \%$ spent on addiction treatment. ${ }^{38}$ Accordingly, the demand for addiction treatment far outweighs availability. ${ }^{39}$ As of 2008, an estimated 176 detoxification beds and 326 long term treatment beds were available in the province of British Columbia (12.11 beds per 100000 population), with a wait time of four to 12 weeks and only 14 beds allocated for mothers with children. ${ }^{40}$ Canada's policy makers have been slow to respond to the shortage of beds in drug treatment facilities. In addition, evidence of the harms of enforcement based strategies is mounting both locally and internationally. ${ }^{41}{ }^{42}$ This research suggests that the failure of the current drug strategy to support women's ability to access treatment may compound experiences of violence among female sex workers. The observational nature of this study precludes determining causality. Nevertheless, qualitative accounts document the role of binge drug use and drug withdrawal in reducing female sex workers' ability to negotiate HIV risk reduction practices with primary partners and clients, which supports our evidence of the potential enhanced vulnerability to violence that results from an unsuccessful attempt to access drug treatment. ${ }^{1819}$ This research underscores the urgent need to improve and scale up access to and availability of drug treatment facilities for female sex workers, including programmes that support pregnant and parenting mothers.

Furthermore, the extremely high prevalence of rape experienced by female sex workers over the 18 month follow-up period points to the immediate need to scale up violence prevention strategies, including increasing support for female sex workers accessing legal and victim services and improving the monitoring of and legal responses to violence against female sex workers. The $63 \%$ elevated likelihood of rape among women who reported reliance on a male partner to procure drugs supports evidence elsewhere of the adverse impact of gender inequities in access to economic or material resources on women's health outcomes. $^{6}$ Rape has been associated with an increased likelihood of acquiring sexually transmitted infections and/or HIV owing to the high likelihood of vaginal and/or rectal trauma; ${ }^{5}$ therefore, the prevention of sexual violence against female sex workers needs to be integrated into HIV prevention efforts. In addition, the independent correlation between rape and consensual unprotected sex with a primary 


\section{WHAT IS ALREADY KNOWN ON THIS TOPIC}

Gender based violence has been identified as a global public health and human rights priority, and leads to high morbidity and mortality

A recent review of gender based violence highlighted how rights violations and abuses against female sex workers are seldom considered in discussions of violence against women

There is a growing body of qualitative evidence documenting the adverse effects of street policing strategies on the health and safety of sex workers

\section{WHAT THIS STUDY ADDS}

Homelessness and inability to access drug treatment were independently correlated with gender based violence against female sex workers, even after adjustment for potential confounding individual and interpersonal risk factors

This study is among the first epidemiological investigations to demonstrate an independent association between criminalisation of and enforcement based approaches to sex work and raised odds of both physical and sexual violence against female sex workers

Our findings support global dialogues on preventative approaches to sex work, including removing criminal sanctions that target female sex workers

partner highlights the risk of sexual transmission of HIV infection and the need for gender transformative and couple focused prevention efforts that target partner violence and sexual decision making. ${ }^{43}$

Finally, the observed relationship between living on the street and the enhanced likelihood of both rape and physical violence highlights the need for structural level responses that focus on poverty and housing, including innovative models of supportive housing that have a harm reduction perspective. Our findings are consistent with previous studies demonstrating an increased likelihood of physical violence among homeless women in substance using populations. ${ }^{44}$ In one study, homeless female sex workers in the United States were more likely than non-homeless female sex workers to report servicing clients who refused to use condoms. ${ }^{45}$ In addition, poverty and drug dependency have been associated with both clients offering and female sex workers accepting more money for unprotected sex..$^{254647}$

\section{Strengths and limitations}

Several potential limitations of our analyses should be considered. Although the observational nature of this research precludes determining causality, our longitudinal analyses using generalised estimating equations and accounting for repeated responses by the same respondent may have reduced some potential temporal bias. Additionally, the use of self reports to measure violence episodes could subject the data to social desirability or response bias. Given the highly stigmatised and criminalised nature of sex work and our qualitative work to date, however, under-reporting of violence episodes would be more likely than overreporting and thus any misclassification would have attenuated estimates towards the null. Furthermore, the use of direct wording in questions on experiences of violence-for example, "have you been physically assaulted in the last 6 months?"- -has been shown to underestimate the incidence of violence against women by failing to account for more ubiquitous episodes of violence, such as slapping. ${ }^{3}$ Similarly, in qualitative work on client perpetrated violence, we have shown that physical violence perpetrated by clients is so commonplace that many women only define "bad dates" as episodes of extreme violence, such as rape. However, we cannot discount the possibility that some variables could be over-reported. In addition, there are always limitations to measuring police violence as it is not possible to distinguish between excessive use of force and legitimate use of force. Finally, given the multiple types of both indoor and outdoor sex work environments - such as establishment sex work venues (for example, bars and massage parlours) or escort agencies - and the differing legal frameworks of prostitution around the world, it might not be possible to generalise our results to other sex work environments or countries.

\section{Conclusions and policy implications}

Our findings document an extremely high prevalence of both sexual and physical violence against female sex workers that persists because of large scale structural inequities. This research provides important empirical evidence demonstrating the adverse public health effects of enforcement based policing approaches to sex work and drug use, and supports global calls to remove criminal sanctions targeting sex workers. Furthermore, our findings suggest that evidence based structural interventions that promote improved access to housing and increased availability of drug treatment will be crucial to stemming the epidemic of violence against street based female sex workers.

Acknowledgements: We thank our community partner, the WISH Drop-In Centre Society, and other community collaborators, research staff, and co-investigators of the Maka Project Partnership. We acknowledge the statistical and data management support provided by Calvin Lai and Ruth Zhang.

Contributors: KS conceptualised the study, developed the data analysis plan, and wrote the original draft of the manuscript. TK, SAS, JS, JSM, and MWT provided content expertise and critical feedback on the analyses and interpretation, and read and approved the final version for submission.

Funding: This research was primarily funded through an operating grant from the HIV/AIDS Community-Based Research Program of the Canadian Institutes of Health Research. KS, TK, and JS are supported by the Canadian Institutes of Health Research. TK and MWT are supported by the Michael Smith Foundation for Health Research. JSM is supported through an Avant-Garde Award from the National Institute on Drug Abuse of the National Institutes of Health. The funders had no role in study design, data collection, or in analysis and interpretation of the results, and this paper does not necessarily reflect views or opinions of the funders. Competing interests: None declared.

1 Watts C, Zimmerman C. Violence against women: global scope and magnitude. Lancet 2002;359:1232-7.

2 United Nations. Declaration on the elimination of violence against women. New York: United Nations General Assembly, 1993.

3 World Health Organization. The third milestones of a global campaign for violence prevention report. Geneva: WHO, 2007.

4 Campbell JC. Health consequences of intimate partner violence. Lancet 2002;359:1331-6.

5 Maman S, Campbell J, Sweat MD, Gielen AC. The intersections of HIV and violence: directions for future research and interventions. Soc Sci Med 2000;50:459-78.

6 Dunkle KL, Jewkes RK, Brown HC, Gray GE, McIntryre JA, Harlow SD. Gender-based violence, relationship power, and risk of HIV infection 
in women attending antenatal clinics in South Africa. Lancet 2004;363:1415-21.

7 Gupta P. How men's power over women fuels HIV epidemic. BMJ 2002;324:183-4.

8 El-Bassel N, Gilbert L, Wu E, Go H, Hill J. HIV and intimate partner violence among methadone-maintained women in New York City. Soc Sci Med 2005;61:171-83.

9 Gilbert L, El-Bassel N, Schilling RF, Catan V, Wada T. Partner abuse and sexual risk behaviour among women on methadone. Violence Vict 1998;13:1-17.

10 Ward H, Pallecaros A, Green A, Day S. Health issues associated with increasing use of "crack" cocaine among female sex workers in London. Sex Transm Infect 2000;76:292-3.

11 UNAIDS. Sex work and HIV/AIDS. Geneva: Joint United Nations Programme on HIV/AIDS, 2002.

12 Canadian HIV/AIDS Legal Network. A Human Rights-based Commentary on UNAIDS Guidance Note: HIV and Sex Work (April 2007). Toronto, Canada: Canadian HIV/AIDS Legal Network, 2007.

13 Goodyear M, Cusick L. Protection of sex workers. BMJ 2007;334:52-3.

14 Goodyear M, Lowman J, Fischer B, Green M. Prostitutes are people too. Lancet 2005;366:1264-5.

15 Lowman J. Reconvening the federal committee on prostitution law reform. CMA/ 2004:171:147-8.

16 Rekart M. Sex-work harm reduction. Lancet 2005;366:2123-34.

17 Blankenship KM, Koester S. Criminal law, policing policy, and HIV risk in female street sex workers and injection drug users..J Law Med Ethics 2002;30:548-59.

18 Shannon K, Kerr T, Allinott S, Chettiar J, Shoveller JS, Tyndall MW. Social and structural violence and power relations in mitigating HIV risk of drug-using women in survival sex work. Soc Sci Med 2008;66:911-21.

19 Maher L. Sexed work: Gender, Race and Resistance in a Brooklyn Drug Market. Oxford: Clarendon Press, 1997.

20 Rhodes T, Simic M, Baros S, Platt L, Zikic B. Police violence and sexual risk among female and transvestite sex workers in Serbia: qualitative study. BMJ 2008;337:a811.

21 Miller CL, Firestone, M, Ramos, R, Burris, S, Ramos, ME, Case P, et al. Injecting drug users' experiences of policing in two Mexican-US cities. Int J Drug Policy 2008;19:324-31.

22 Spittal PM, Hogg RS, Li K, Craib KJ, Recsky M, Johnston C, et al. Drastic elevations in mortality among female injection drug users in a Canadian setting. AIDS Care 2006;18:101-8.

23 Cost of Pickton trial could rival \$130-million Air India case. Ottawa Citizen 5 December

2007. http://www.canada.com/ottawacitizen/news/story.html? id=4e9e3a1e-d690-41d1-a724-0d3416b4b65e.

24 Shannon K, Bright V, Parsad D, Alexson D, Allinott S, Gibson K, et al. Community-based HIV prevention research among substance-using women in survival sex work: the Maka Project Partnership. Harm Reduct J 2007;4:20-6.

25 Shannon K, Kerr T, Bright V, Gibson K, Tyndall MW. Drug sharing with clients as a risk marker for increased violence and sexual and drug. related harms among survival sex workers. AIDS Care 2007;20:235-41.

26 Stueve A, O’Donnell LN, Duran R, San Doval A, Blome J. Time-space sampling in minority communities: results with young Latino men who have sex with men. Am J Public Health 2001;91:922-6.

27 Pyett PM, Warr DJ. Vulnerability on the streets: female sex workers and HIV risk. AIDS Care 1997;9:539-47.
28 Lowman L. Violence and the outlaw status of (street) prostitution in Canada. Violence Against Women 2000;6:987-1011.

29 Church S, Henderson, M, Barnard M, Hart G. Violence by clients towards female prostitutes in different work settings: questionnaire survey. BMJ 2001;322:524-5.

30 Brooks-Gordon B. State violence towards sex workers. $B M$ 2008;337:a908.

31 WHO. World Report on Violence and Health. Geneva, Switzerland World Health Organization, 2002.

32 Cooper H, Moore L, Gruskin S, Krieger N. Characterizing perceived police violence: implications for public health. Am J Public Health 2004;94:1109-18.

33 Human Rights Watch. Abusing the user. Police misconduct, harm reduction and HIV/AIDS in Vancouver. New York: Human Rights Watch, 2003.

34 Werb D, Wood E, Small W, Strathdee S, Li K, Montaner J, et al. Effects of police confiscation of illicit drugs and syringes among injection drug users in Vancouver. Intl J Drug Policy 2008;9:332-8.

35 Aitken C, Moore D, Higgs P, Kelsall J, Kerger M. The impact of a police crackdown on a street drug scene: evidence from the street. Int J Drug Policy 2002;13:189-198.

36 Wood E, Spittal PM, Small W, Kerr T, Li K, Hogg RS, et al. Displacement of Canada's largest public illicit drug market in response to a police crackdown. CMA/ 2004;170:1551-6.

37 Shannon K, Strathdee SA, Shoveller J, Rusch M, Kerr T, Tyndall MW. Structural and environmental barriers to condom use negotiation with clients among women in survival sex work: Implications for HIV prevention strategies and policy. Am J Public Health 2009;99:659-65.

38 DeBeck K, Wood E, Montaner J, Kerr T. Canada's 2003 renewed drug strategy -an evidence-based review. HIV AIDS Policy Law Rev 2006;11:5-12.

39 Wood E, Spittal PM, Li K, Kerr T, Miller CL, Hogg RS, et al. Inability to access addiction treatment and risk of HIV-infection among injection drug users. J Acquir Immune Defic Syndr 2004;36:750-4.

40 Paperny AM. Losing the drive to quit: clinging to the cracks in the detox system. The Globe and Mail, 2008.

41 Davis CS, Burris S, Kraut-Becher J, Lynch KG, Metzger D. Effects of an intensive street-level police intervention on syringe exchange program use in Philadelphia. Am J Public Health 2005;95:233-6.

42 Wood E, Spittal PM, Small W, Kerr T, Li K, Hogg RS, et al. Displacement of canada's largest public illicit drug market in response to a police crackdown. CMAJ 2004;170:1551-6.

43 Dunkle KL, Jewkes R. Effective HIV prevention requires gendertransformative work with men. Sex Transm Infect 2007;83:173-4.

44 Wenzel SL, Leake BD, Gelberg L. Risk factors for major violence among homeless women. J Interpersonal Viol 2001;16:739-52

45 Surratt H, Inciardi JA, Kurtz SP, Kiley MC. Sex work and drug use in a subculture of violence. Crime Deling 2004;50:43-59.

46 Ntumbanzonda M, Dubrow R, Niccolai LM, Mwandagalirwa K, Merson $\mathrm{MH}$. Unprotected intercourse for extra money among commercial sex workers in Kinshasa, Democratic Republic of Congo. AIDS Care 2006;18:777-85.

47 Strathdee SA, Semple SJ, Pu M, Orozovich P, Martinez G, Lozada R, et al. Correlates of injection drug use among female sex workers in two Mexico-U.S. border cities. Drug Alcohol Depend 2008;92:132-40.

Accepted: 8 March 2009 